\title{
Malignant Myoepithelioma of the Parotid Gland: Literature Review on the Occasion of Our Report of a Case
}

\author{
George Kyrgias $^{1,2}$, Maria-Aggeliki Kalogeridi ${ }^{1}$, John Tzitzikas $^{3}$, Vassilios Kouloulias $^{4}$ \\ ${ }^{1}$ Radiation Oncology Department, University Hospital of Larissa, Thessaly, Greece; ${ }^{2}$ Medical School, University of Thessaly, Larissa, \\ Greece; ${ }^{3}$ Radiation Oncology Department, American Hellenic Educational Progressive Association, University Hospital, Thessalo- \\ niki, Greece; ${ }^{4}$ Radiotherapy Unit—2nd Department of Radiology, National and Kapodistrian University, Athens, Greece. \\ Email: gkyrgias@gmail.com,gkyrgias@med.uth.gr
}

Received October $5^{\text {th }}, 2011$; revised November $6^{\text {th }}, 2011$; accepted December $13^{\text {th }}, 2011$

\begin{abstract}
Malignant myoepitheliomas are rare malignant salivary gland neoplasms which usually occur in the parotid gland. Very little material on this topic has been published. This tumour represents a therapeutic challenge since there are no specific recommendations or guidelines. We present a case of malignant myoepithelioma arising de novo in the parotid gland. We discuss our therapeutic approach and considerations on appropriate post-surgical treatment. Then we provide a review of international literature on this interesting and rare oncological entity.
\end{abstract}

Keywords: Malignant Myoepithelioma; Parotid; Radiotherapy; Rare Neoplasms; Review

\section{Introduction}

Myoepitheliomas of the salivary glands are rare tumours, accounting for about $1 \%$ of all salivary gland tumours [1-3]. Most of them are benign and only $10 \%$ are malignant [1]. Most malignant myoepitheliomas occur in the parotid gland $[1,4,5]$.

To our knowledge, in medical publications in English, the first report of a case of a malignant myoepithelioma (MM) of a minor salivary gland was in 1975 by Stromeyer et al. [6] while the first case of a MM of the parotid gland was reported in 1977 by Crissman et al.; the latter presented the case of a locally aggressive MM that eventually metastasized [7]. Further reports on malignant myoepitheliomas (MMs) have been generally scarce.

Our search in pubmed, particularly focused on the last 35 years (between the years 1975 and 2010) revealed only a few dozen posts on salivary gland myoepitheliomas. Most of these concerned tumours of the parotid gland, whilst a smaller number of them were about minor salivary gland tumours. There have also been sporadic reports of MM at unusual sites, e.g., the breast, bone, external auditory canal, skin and vulva. The majority of these reports deal with the clinical and pathologic or the immunohistochemical features and complexities of the tumour [4,8-18] but offer limited data concerning the treatment.

In this paper, written on the occasion of a patient presenting with an MM of the parotid, we provide a review of previous publications concerning the issue.

\section{Case Report}

A 72-year old man presented with a painless mass in the right parotid region. The mass, which had progressed slowly the last few months, was firm on examination. The patient was referred for a fine needle aspiration and the cytology revealed a malignant epithelial tumour.

The patient was submitted to a partial right parotidectomy with free margins and lymph node dissection. The histological analysis showed a grade 2-malignant myoepithelioma predominantly made up of epithelioid cells but a spindle cell component was also present. Mitotic figures and nuclear pleomorphism were also observed. Neoplastic cells were growing as multiple nodules with extended central necrosis. These results match the description of an MM [11]. There were focal regions of tumour cells infiltrating the capsule but tumour infiltration into the adjacent parotid tissue was absent. Immunohistochemical reaction was strongly positive for S-100 protein and vimentin.

The patient was referred for postoperative radiotherapy. Using two ipsilateral $6 \mathrm{MV}$ photon beams [anterior oblique and posterior oblique] we delivered a total dose of $60 \mathrm{~Gy}$ to the tumour bed and the right parotid region, with a conventional fractionation of $2 \mathrm{~Gy} /$ fraction, five fractions per week, for a total duration of six weeks. A thermoplastic mask was used as an immobilization device during the simulations and the treatment as a whole.

The patient completed the irradiation with a satisfactory treatment tolerance; acute toxicity included only 
grade I-II dermatitis and a slight, grade I-toxicity of the buccal mucosa was evident. Eleven months after the completion of the radiotherapy treatment the patient died as a result of undercurrent heart disease, without any evidence of local or regional relapse of the myoepithelioma or any late side effect of the radiotherapy.

\section{Review}

Myoepitheliomas of the salivary glands are rare tumours that occur mostly in the parotid gland $[1,4,5]$. However, other head and neck sites of origin such as the submandibular gland [19,20] oral cavity [21], palate [3,4,22-25] larynx [26,27], parapharyngeal space [28], nasopharynx [29-32], maxillary sinus [33], external auditory canal [34] have, rarely, been reported in the literature. MMs have also been, sporadically, reported in unusual locations, e.g., the breast [35-37], bone [38-40] skin [41] and vulva [42].

Malignant myoepithelioma of the parotid may occur within pre-existing benign lesions like pleomorphic adenomas [8,9,13,43-45] or benign myoepitheliomas, but may also occur de novo $[9,13,19,43,46,47]$. These tumours are distinguished from their benign myoepithelial counterparts by their infiltrating and destructive growth, cellular pleomorphism and mitotic figures [48]. According to a recent report by Darvishian and Lin the malignant features of myoepithelial carcinoma arising mainly in the salivary glands are pleomorphism, coarse chromatine, prominent nucleoli, mitotic figures and/or necrosis [49].

Histologically, MMs are composed of one or several cell types: spindle, plasmacytoid, epithelioid and clear cells [23]. The mean age of presentation is 62 years [1] and a slow-growing painless mass is usually involved [28].

Imaging features of myoepitheliomas of the parotid gland rarely appear in the literature because of the low prevalence of the tumours. By means of ultrasonography, CT and MRI, myoepitheliomas have been described to be well circumscribed, mass lesions with smooth or lobulated margins. They may be solid lesions or contain both cystic and solid components. Following intravenous contrast medium injection at CT and MRI, the lesions may exhibit either homogeneous or inhomogeneous enhancement. They are usually depicted in the superficial lobe of the parotid gland and less frequently found in the deep lobe or the tail of the gland [50-52].

As myoepithelioma of the parotid is not a common tumour, there are no specific guidelines for its treatment. Complete resection with wide margins is considered essential and has given favourable outcomes for salivary gland myoepitheliomas $[5,14,22]$. Until now the mainstay of treatment has been surgery $[22,28]$. Malignant myoepithelial cell-rich lesions require a wider local excision and lymph node dissection [49].

According to a retrospective study of 27 cases of myoepithelial carcinoma of the salivary glands the tumour is characterised by extensive local growth and invasion of the surrounding tissues. Although cervical lymph node metastasis is infrequent [53], there are high rates of distant metastases [5].

There are reports of malignant myoepitheliomas presenting with secondary lesions to the lung $[10,54]$ liver [26], skin [55] or lymph nodes [10], while others have a tendency to recur locally $[10,54]$.

For our review, some of the above data are summarized on the tables, i.e.: Table 1 summarizes the references of MMs of salivary glands (all sites), and Table 2 summarizes the number of MMs of parotid gland referred in the international literature with the special features of each reference.

There is extremely limited data concerning radiotherapy for this rare tumour. The first use of radical radiotherapy in MM was reported in 2009, concerning a 90-year-old man with impaired performance status and a $\mathrm{MM}$ of the soft palate. Radiotherapy gave excellent palliative effect and local control [22].

In our case, presented in this paper, the patient was re-

Table 1. Malignant myoepitheliomas of salivary glands: number of cases per reference and per site.

\begin{tabular}{|c|c|c|c|c|c|}
\hline \multirow{2}{*}{ References } & \multirow{2}{*}{$\begin{array}{l}\text { Total } \\
\text { cases }\end{array}$} & \multicolumn{4}{|c|}{ Cases per site } \\
\hline & & Parotid & Submandibular & Sublingual & Minor salivary glands \\
\hline Sciubba et al. (1982) [2] & 23 & 12 & 5 & --- & 6 (5 intraoral, 1 upper lip) \\
\hline Yu G. et al. (2003) [5] & 27 & 14 & 4 & 1 & 8 (7 palate, 1 base of tongue) \\
\hline Savera et al. (2000) [47] & $25^{\mathrm{a}}$ & 15 & 4 & --- & $\begin{array}{l}5 \text { ( } 2 \text { palate, } 1 \text { maxill sinus, } 1 \text { tongue (base), } 1 \text { supragl } \\
\text { larynx }\end{array}$ \\
\hline Di Palma et al. (1993) [54] & 10 & 8 & --- & -- & 2 (1 palate, 1 cheek) \\
\hline Alos et al. (1996) [55] & $4^{\mathrm{b}}$ & 2 & --- & --- & 2 (NOS) \\
\hline
\end{tabular}

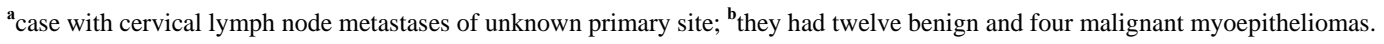


Table 2. Malignant myoepitheliomas of the parotid gland: number of cases per reference and special features.

\begin{tabular}{|c|c|c|}
\hline MM of parotid gland & No of cases & Special features \\
\hline Crissman et al. (1997) [7] & 1 & PMM locally aggressive and eventually metastasized \\
\hline DiPalma et al. (1996) [8] & 5 & Almost all PMMs initially thought to be recurrent pleomorphic adenomas \\
\hline Singh et al. (1988) [9] & 1 & PMM arising in a pleomorphic adenoma \\
\hline Klumpp et al. (1995) [10] & 1 & $\begin{array}{l}\text { Local, regional and metastatic progression prior to completion of adjuvant } \\
\text { RT }\end{array}$ \\
\hline Chow et al. (1996) [11] & 1 & PMM's cytologic features in FNA \\
\hline Sironi et al. (1997) [12] & 1 & PMM's cytologic, immunocytochemical and ultrastructural study \\
\hline Daneshbod et al. (2007) [13] & 1 & PMM arising in a pleomorphic adenoma \\
\hline Gun et al. (2009) [15] ${ }^{15}$ & 1 & PMM with histological uncertainties \\
\hline Siddarayu et al. (2008) [16] & 1 & PPM's preoperative FNA cytologic diagnosis \\
\hline Shinozaki et al. (2008) [17] & 42 & $\begin{array}{l}\text { Six out of forty-two with sebaceous differentiation (histological variant of } \\
\text { PMM) }\end{array}$ \\
\hline Lauro et al. (2003) [43] & 1 & PMM arising in a pleomorphic adenoma \\
\hline Di Palma et al. (1991) [44] & 1 & PMM arising in a pleomorphic adenoma \\
\hline Di Palma et al. (1998) [45] & 1 & PMM arising in a pleomorphic adenoma \\
\hline Dardick et al. (1989) [7] & 5 & PMM’s histological, ultrastructural, and immunocytological features \\
\hline Maurer et al. (2009) [50] & 1 & CT and MRI in the differentiation between PBM and PMM \\
\hline Wang et al. (2008) [51] & 10 & PMM’s CT imaging findings \\
\hline Lee et al. (2005) [52] & 2 & $\begin{array}{l}\text { PMMs clinically suspected to be infra-auricular subcutaneous epidermal } \\
\text { cysts }\end{array}$ \\
\hline
\end{tabular}

MM: Malignant Myoepithelioma; PMM: Parotideal Malignant Myoepithelioma; PBM: Parotideal Benign Myoepithelioma; FNA: Fine Needle Aspiration; RT: Radiation Therapy; CT: Computerized Tomography; MRI: Magnetic Resonance Imaging.

ferred for adjuvant radiotherapy after a partial parotidectomy and lymph node dissection. Although, according to the pathological report, we had negative surgical margins and no lymph node infiltration, we decided to proceed with adjuvant radiation therapy for the following reasons:

- The surgeon had expressed concerns about tumour spillage during the removal.

- There were focal regions of tumour cells infiltrating the capsule.

- There are no specific guidelines for the post-surgical treatment of a malignant myoepithelioma, but MM of the salivary glands has a relatively high tendency to recur locally [18]. There are, indeed, some reports in the literature on MMs of the head and neck region that recurred locally after successful surgical excision [10,25].

- As in this case, tumours that display marked histological aggressiveness [high mitotic rate, necrosis] may behave adversely.

- It is known that MMs arising de novo in a normal salivary gland, as in this case, tend to be more aggressive [54].

\section{Conclusion}

Malignant myoepitheliomas are rare tumours with no specific guidelines for their treatment. Based on a literature review of reports of local recurrence of head and neck MMs after successful surgical excision, we believe that radiotherapy to MM of the parotid should be considered as a treatment of choice in conjunction with chemotherapy. Reported acute toxicity is minimal, while regular follow-up of the patient is necessary to report longterm toxicity of radiotherapy as well as local control of the disease. Metastases of a myoepithelioma are a rare event. As a result there is little material available as guidance and each instance should be assessed on a caseby-case basis.

\section{REFERENCES}

[1] T. Nagao, I. Sugano, Y. Ishida, Y. Tajima, O. Matsuzaki, A. Konno, Y. Kondo, et al., "Salivary Gland Malignant Myoepithelioma: A Clinicopathologic and Immunohistochemical Study of Ten Cases," Cancer, Vol. 83, No. 7, 1998, pp. 1292-1299. doi:10.1002/(SICI)1097-0142(19981001)83:7<1292::AID -CNCR4>3.0.CO;2-L

[2] J. J. Sciubba and R. B. Brannon, "Myoepithelioma of the Salivary Glands: Report of 23 Cases,” Cancer, Vol. 49, No. 3, 1982, pp. 562-572. doi:10.1002/1097-0142(19820201)49:3<562::AID-CNCR $\underline{2820490328>3.0 . C O ; 2-6}$ 
[3] L. Barnes, B. N. Appel, H. Perez and A. M. El-Attar, “Myoepithelioma of the Head and Neck: Case Report and Review," Journal of Surgical Oncology, Vol. 28, No. 1, 1985, pp. 21-28. doi:10.1002/jso.2930280107

[4] M. F. Acikalin, O. Pasaoglu, H. Cakli, K. Gurbuz and F. Canaz, "Malignant Myoepithelioma of the Palate: A Case Report with Review of the Clinopathological Characteristics,” Yonsei Medical Journal, Vol. 50, No. 6, 2009, pp. 848-851. doi:10.3349/ymj.2009.50.6.848

[5] G. Yu, D. Ma, K. Sun, T. Li and Y. Zhang, "Myoepithelial Carcinoma of the Salivary Glands: Behaviour and Management," Chinese Medical Journal, Vol. 116, No. 2, 2003, pp. 163-165.

[6] F. W. Stromeyer, R. C. Haggitt, J. F. Nelson and J. M Hardman, "Myoepithelioma of Minor Salivary Gland Origin. Light and Electron Microscopical Study," Archives of Pathology, Vol. 99, No. 5, 1975, pp. 242-245.

[7] J. D. Crissman, J. A. Wirman and A. Harris, "Malignant Myoepithelioma of the Parotid Gland," Cancer, Vol. 40, No. 6, 1997, pp. 3042-3049. doi:10.1002/1097-0142(197712)40:6<3042::AID-CNCR2 820400642>3.0.CO;2-N

[8] S. DiPalma, L. Alasio and S. Pilotti, "Fine Needle Aspiration (FNA) Appearances of Malignant Myoepithelioma of the Parotid Gland,” Cytopathology, Vol. 7, No. 5, 1996, pp. 357-365. doi:10.1111/j.1365-2303.1996.tb00315.x

[9] R. Singh and R. A. Cawson, "Malignant Myoepithelial Carcinoma (Myoepithelioma) Arising in a Pleomorphic Adenoma of the Parotid Gland. An Immunohistochemical Study and Review of the Literature," Oral Surgery, Oral Medicine, Oral Pathology, Vol. 66, No. 1, 1988, pp. 6570. doi:10.1016/0030-4220(88)90069-2

[10] T. R. Klumpp, R. M. Mohr, C. L. Silverman, C. K. Tanq, I. B. Elfenbein and I. Dardick, "Malignant Myoepithelioma of the Parotid Gland: Case Report and Review of the Literature,” Journal of Laryngology and Otology, Vol. 109, No. 10, 1995, pp. 995-998.

[11] L. T. Chow, W. H. Chow and J. C. Lee, "Monomorphic EPithelioid Variant of Malignant Myoepithelioma of the Parotid Gland: Cytologic Features in Fine Needle Aspiration (FNA)," Cytopathology, Vol. 7, No. 4, 1996, pp. 279287. doi:10.1046/j.1365-2303.1996.40482404.x

[12] M. Sironi, G. Taccagni and A. Assi, "A Cytologic, Immunocytochemical and Ultrastructural Study of a Malignant Parotid Gland Myoepithelioma,” Cytopathology, Vol. 8, No. 1,1997 , pp. 53-62. doi:10.1046/j.1365-2303.1997.41275412.x

[13] Y. Daneshbod, S. Negahban, B. Khademi and K. Daneshbod, "Epithelial Myoepithelial Carcinoma of the Parotid Gland with Malignant Ductal and Myoepithelial Components Arising in a Pleomorphic Adenoma: A Case Report with Cytologic, Histologic and Immunohistochemical Correlation,” Acta Cytologica, Vol. 51, No. 5, 2007, pp. 807813. doi:10.1159/000325847

[14] F. Angiero, D. Sozzi, R. Seramondi and M. G. Valente, "Epithelial-Myoepithelial Carcinoma of the Minor Salivary Glands: Immunohistochemical and Morphological Features,” Anticancer Research, Vol. 29, No. 11, 2009, pp. 4703-4709.
[15] B. D. Gun, S. O. Ozdamar, B. Bahadir and L. Uzun, “Salivary Gland Myoepithelioma with Focal Capsular Invasion," Ear, Nose, and Throat Journal, Vol. 88, No. 7, 2009, pp. 1005-1009.

[16] N. Siddaraju, B. A. Badhe, M. Goneppanavar and M. M. Mishra, "Preoperative Fine Needle Aspiration Cytologic Diagnosis of Spindle Cell Myoepithelioma of the Parotid Gland: A Case Report,” Acta Cytologica, Vol. 52, No. 4, 2008, pp. 495-499. doi:10.1159/000325561

[17] A. Shinozaki, T. Nagao, H. Endo, N. Kato, M. Hirokawa, K. Mizobuchi, M. Komatsu, et al., "Sebaceous EpithelialMyoepithelial Carcinoma of the Salivary Gland: Clinicopathologic and Immunohistochemical Analysis of 6 Cases of a New Histologic Variant," The American Journal of Surgical Pathology, Vol. 32, No. 6, 2008, pp. 913-923. doi:10.1097/PAS.0b013e318160852a

[18] Q. L. Liao, L. H. Li, R. Q. Lai, X. D. Chen, J. W. Chen and Y. M. Zhou, "Clinical and Pathologic Features of Malignant Myoepithelioma of Salivary Glands,” Chinese Journal of Pathology, Vol. 34, No. 4, 2005, pp. 211-214.

[19] A. N. Erkan, N. Bal, F. Caylakli and F. Kiroglu, "Epithelial-Myoepithelial Carcinoma of the Submandibular Gland: A Case Report,” Kulak Burun Bogaz Ihtis Derg, Vol. 17, No. 3, 2007, pp. 167-170.

[20] J. V. Nayak, J. T. Molina, J. C. Smith, B. F. Branstetter IV, J. L. Hunt and C. H. Snyderman, "Myopithelial Neoplasia of the Submandibular Gland: Case Report and Therapeutic Considerations," Archieves of Otolaryngology Head \& Neck Surgery, Vol. 129, No. 3, 2003, pp. 359-362.

[21] S. Yang, L. Li, M. Zeng, X. Zhu, J. Zhang and X Chen, "Myoepithelial Carcinoma of Intraoral Minor Salivary Glands: A Clinicopathological Study of 7 Cases and Review of the Literature," Oral Surgery Oral Medicine Oral Pathology Oral Radiology and Endodontics, Vol. 110, No. 1, 2010, pp. 85-93. doi:10.1016/j.tripleo.2010.02.023

[22] S. R. oumarova, Z. Lovasova, M. Vankova and L. Sokol, "Radiotherapy in Malignant Myoepithelioma of the Soft Palate-Case Report," Case Reports in Oncology, Vol. 17, No. 2, 2009, pp. 116-120. doi:10.1159/000228546

[23] H. Kuwabara, H. Uda, K. iyabe, K. Saito and T. Shibanushi, "Malignant Plasmacytoid Myoepithelioma of the Palate: Histological Observations Compared to Benign Predominant Plasmacytoid Myoepithelial Cells in Pleomorphic Adenoma of the Palate," Ultrastructuaral Pathology, Vol. 22, No. 2, 1998, pp. 153-160. doi:10.3109/01913129809032271

[24] M. Guzzo, G. Cantu and S. Di Palma, "Malignant Myoepithelioma of the Palate: Report of Case," Journal of Oral and Maxillofacical Surgery, Vol. 52, No. 10, 1994, pp. 1080-1082. doi:10.1016/0278-2391(94)90183-X

[25] L. G. Patrocinio, P. G. Damasceno and J. A. Patrocinio, "Malignant Myoepithelioma of the HArd Palate: 9-Year Follow-Up," Brazilian Journal of Otorhinolaryngology, Vol. 75, No. 4, 2009, p. 620. doi:10.1590/S1808-86942009000400025

[26] R. Ibrahim, D. J. Bird and M. W. Sieler, "Malignant Myoepithelioma of the LArynx with Massive Metastatic Spread to the Liver: An Ultrastructural and Immunocytochemical Study," Ultrastructural Pathology, Vol. 15, No. 
1, 1991, pp. 69-76. doi:10.3109/01913129109021305

[27] G. H. Yu, G. M. Qu, L. L. Kong, X. B. Pan, W. Wang and J. W. Lv, "Primary Myoepithelial Carcinoma of the Larynx: Case Report and Review of the Literature,” $\mathrm{Pa}$ thology Research and Practice, Vol. 207, No. 2, 2011, pp. 127-130. doi:10.1016/j.prp.2010.10.006

[28] K. Ramachandran, M. Venugopal, R. Suma and K. C. Naseer, "Malignant Myoepithelioma of the Parapharyngeal Space-A Case Report,” Indian Journal of Otolaryngology and Head \& Neck Surgery, Vol. 60, No. 2, 2008, pp. 174-176. doi:10.1007/s12070-008-0042-9

[29] G. Magliulo, G. Pulice, M. Fusconi and G. Cuiuli, "Malignant Myoepithelioma of the Rhinopharynx: Case Report,” Skull Base, Vol. 15, No. 2, 2005, pp. 113-116. doi:10.1055/s-2005-870596

[30] R. Nilles, T. Lenartz and E. Kaiserling, "Myoepithelial Carcinoma of the Nasopharynx. Case Report and Review of the Literature,” HNO, Vol. 41, No. 8, 1993, pp. 396400.

[31] F. Nofal, "Spindle Cell CArcinoma of the Nasopharynx," The Journal of Laryngology and Otology, Vol. 97, No. 1, 1983, pp. 1057-1063. doi:10.1017/S0022215100095979

[32] U. Tuncel, G. Ergul, S. Ozlugedik and A. Unal, "Myoepithelial Carcinoma in the Nasopharynx: An Unusual Localization,” Yonsei Medicine Journal, Vol. 45, No. 1, 2004, pp. 161-165.

[33] M. Hata, K. Tokuuye, Y. Shioyama, S. Nomoto, Y. Inadome, N. Fukumitsu, H. Nakayama, et al., "Malignant Myoepithelioma in the Maxillary Sinus: Case Report and Review of the Literature," Anticancer Research, Vol. 29, No. 2, 2009, pp. 497-501.

[34] A. Dirier, A. Guzel, B. Karadayi, S. O. Ozekinci and M. Tatli, "Malignant Myoepithelioma of the External Auditory Canal: A Case Report,” International Journal of Clinical Practice, Vol. 63, No. 2, 2009, pp. 336-337. doi:10.1111/j.1742-1241.2006.01021.x

[35] T. Terada, "Malignant Myoepithelioma of the Breast," $\mathrm{Pa}$ thology International, Vol. 61, No. 2, 2011, pp. 99-103. doi:10.1111/j.1440-1827.2010.02638.x

[36] L. Hegyi, K. Thway, R. Newton, P. Osin, A. Nerurkar, A. J. Hayes and C. Fisher, "Malignant Myoepithelioma Arising in Adenomyoepithelioma of the Breast and Coincident Multiple Gastrointestinal Stromal Tumours in a Patient with Neurofibromatosis Type 1," Journal of Clinical Pathology, Vol. 62, No. 7, 2009, pp. 653-655. doi:10.1136/jcp.2008.063628

[37] Z. M. Fang, R. V. Tse, V. M. Marjoniemi, S. Kozlov, M. F. Lavin, H. Chen, J. H. Kearsley, et al., "Radioresistant Malignant Myoepithelioma of the Breast with High Level of Ataxia Telangiectasia Mutated Protein,” Journal of Medical Imaging and Radiation Oncology, Vol. 53, No. 2, 2009, pp. 234-239.

[38] J. S. Park, K N. Ryu, C. S. Han and Y. K. Park, "Malignant Myoepithelioma of the Humerus with a Satellite Lesion: A Case Report and Literature Review," British Journal of Radiology, Vol. 83, No. 991, 2010, pp. e161e164. doi:10.1259/bjr/64670838

[39] M. Alberghini, G. Pasquinelli, L. Zanella, G. Pignatti, S.
Benini, P. Bacchini and F. Bertoni, "Primary Malignant Myoepithelioma of the Distal Femur,” APMIS, Vol. 115, No. 4, 2007, pp. 376-380. doi:10.1111/j.1600-0463.2007.apm_569.x

[40] J. C. Clark, S. J. Galloway, S. M. Schlicht, R. P. McKellar and P. F. Choong, "Myoepithelioma within the Carpal Tunnel: A Case Report and Review of the Literature," International Seminars in Surgical Oncology, Vol. 6, 2009, p. 15. doi:10.1186/1477-7800-6-15

[41] Z. Stojsic, D. Brasanac, I. Boricic and D. Bacetic, "Clear Cell Myoepithelial Carcinoma of the Skin. A Case Report,” Journal of Cutaneous Pathology, Vol. 36, No. 6, 2009, pp. 680-683. doi:10.1111/j.1600-0560.2008.01095.x

[42] M. S. Mukhina, N. A. Maksimova, N. S. Safina and I. A. Chizh, "Malignant Vulvar Soft Tissue Myoepithelioma," Arkhiv Patolgii, Vol. 71, No. 2, 2009, pp. 18-19.

[43] S. Lauro, L. Trasatti, G. Larosa, F. Calabretta, C. R. Di Gioia and A. Vecchione, "Myoepithelial Carcinoma of Parotid Gland: A Case Report,” Anticancer Research, Vol. 23, No. 3C, 2003, pp. 3041-3044.

[44] S. Di Palma, S. Pilotti and F. Rilke, "Malignant Myo-epithelioma of the Parotid Gland Arising in a Pleomorphic Adenoma," Histopathology, Vol. 19, No. 3, 1991, pp. 273275. doi:10.1111/j.1365-2559.1991.tb00034.x

[45] S. Di Palma and M. Guzzo, "Myoepithelial Carcinoma with Predominance of Plasmacytoid Cells Arising in a Pleomorphic Adenoma of the Parotid Gland," Histopathology, Vol. 33, No. 5, 1998, p. 485. doi:10.1046/j.1365-2559.1998.0491b.x

[46] J. Li, Z. Tian, M. Brandwein-Gensler, H. Y. Pan, L. Li, A. R. Liu, "De Novo Salivary Malignant Myoepithelioma: Pathologic Diagnosis of 19 Cases," Chinese Journal of Stomatology, Vol. 39, No. 4, 2004, pp. 287-290.

[47] A. T. Savera, A. Sloman, A. G. Huvos and D. S. Klimstra, "Myoepithelial Carcinoma of the Salivary Glands: A Clinicopathologic Study of 25 Patients," The American Journal of Surgical Pathology, Vol. 24, No. 6, 2000, pp. 761774. doi:10.1097/00000478-200006000-00001

[48] I. Dardick, S. Cavell, M. Boivin, D. Hoppe, W. R. Parks, J. Stinson, S. Yamada, et al., "Salivary Gland Myoepithelioma Variants Histological, Ultrastructural and Immunocytological Features," Virchows Archiv, Vol. 416, No. 1, 1989, pp. 25-42. doi:10.1007/BF01606467

[49] F. Darvishian and O. Lin, "Myoepithelial Cell-Rich Neoplasms: Cytologic Features of Benign and Malignant Lesions," Cancer, Vol. 102, No. 6, 2004, pp. 355-361. doi:10.1002/cncr.20642

[50] M. H. Maurer, S. Gartenschlager, C. Dietrich, "Giant Epithelial-Myoepithelial Carcinoma of the Parotid Gland,” Clinical Imaging,Vol. 33, No. 3, 2009, pp. 237-239. doi:10.1016/j.clinimag.2008.11.013

[51] S. Wang, H. Shi, L. Wang and Q. Yu, "Myoepithelioma of the Parotid Gland: CT Imaging Findings," American Journal of Neuroradiology, Vol. 29, No. 7, 2008, pp. 13721375. doi:10.3174/ajnr.A1109

[52] M. W. Lee, S. Y. Nam, H. J. Choi, J. H. Choi, K. C. Moon and J. K. Koh, "Myoepithelioma of Parotid Gland Pre- 
senting as Infra-Auricular Subcutaneous Mass,” Journal of Cutaneous Pathology, Vol. 32, No. 3, 2005, pp. 240-244. doi:10.1111/j.0303-6987.2005.00293.x

[53] M. Jain, S. Thomas and S. Singh, "Epithelial Myoepithelial Carcinoma of Minor Salivary Gland-Low Grade Malignant Tumor Presenting with Nodal Metastasis," Indian Journal of Pathology and Microbiology, Vol. 49, No. 3, 2006, pp. 399-401.

[54] S. Di Palma and M. Guzzo, "Malignant Myoepithelioma of Salivary Glands: Clinicopathological Features of Ten Cases,” Virchows Arch, Vol. 423, No. 50, 1993, pp. 389396. doi:10.1007/BF01607152

[55] L. Alos, A. Cardesa, J. A. Bombi, C. Mallofre, A. Cuchi and J. Traserra, "Myoepithelial Tumours of Salivary Glands: A Clinicopathologic, Immunohistochemical, Ultrastructural and Flow-Cytometric Study," Seminars in Diagnostic Pathology, Vol. 13, No. 2, 1996, pp. 138-147. 